\title{
ASSOCIATION BETWEEN ANKYLOSING SPONDYLITIS AND CHRONIC PERIODONTITIS IN DUHOK: A CASE-CONTROL STUDY
}

\author{
Saeed Ali Mohammed*
}

\begin{abstract}
Background and objectives: Ankylosing spondylitis (AS) and periodontal disease (PD) are characterized by dysregulation of the host inflammatory response, resulting in soft and hard connective tissue destruction. AS has been related toother inflammatory diseases, however, there is a paucity of data on whether AS is associated with inflammatory PD. The aim of this study to investigate the possible association between AS and chronic periodontitis.

Methods: The case-control study included 90 individuals, 45 documented patients with AS and had been diagnosed by rheumatologists in the specialized center of rheumatic disease and medical rehabilitation and referred to the department of periodontics, College of Dentistry, University of Duhok and another 45 clinically healthy individuals with PD as a control group. Among studied individuals, 65 were males and 25 were female. A detailed periodontal examination was performed in all subjects, included probing pocket depth, epithelial insertion level (clinical attachment loss) and plaque index and a form of questionnaires was filled from the patients included gender, age, duration of AS disease, medication, risk factors of PD like smoking and level of education.
\end{abstract}

Results : No significant differences were found in two studied groups based on age groups, level of education, smoking, duration of disease and the type of used drugs, but a significant difference was found between two groups based on gender in which AS was more common among males than females.

Conclusions: These results suggest that an association may exist between AS and periodontal disease. Such an association would be important since knowledge of an effect of periodontal treatment on AS disease activity or vice versa would lead to the need for close collaboration between rheumatologists and dentists when treating these diseases

KEYWORD: Ankylosing spondylitis, Periodontal disease, Periodontitis

\footnotetext{
* Department of Periodontics, College of Dentistry, University of Duhok, Duhok, Kurdistan region, Iraq.
} 


\section{INTRODUCTION}

Periodontal disease (PD) is a pathological concept that brings together inflammatory, proliferative and degenerative changes of marginal periodontal tissue ${ }^{(1)}$. Periodontal disease is progressive and episodic in nature, with tissue destruction resulting from the host response to bacterial antigens and irritants ${ }^{(2)}$.

AS is a chronic inflammatory disease that predominantly affects the spine, starts from sacroiliac joint, has an upward trend and tendency to fibrosis, ossification and eventually stiffening of the spine. Symptoms include morning stiffness, fatigue and chronic morning and/or nocturnal back pain and often this disease leads to functional limitations and resultant disability, as well as to decrease of quality of life ${ }^{(3)}$.

Etiology is unknown and pathogenesis is still incompletely understood, but the most important role is assigned to the HLA-B27 phenotype that is found in $90-95 \%$ of patients ${ }^{(4,5)}$.

Mainly young males in their second or third decade of life are afflicted by AS with a male-female ratio of 2-3:1. The main symptoms a inflammatory back pain and stiffness of the spine Both AS and $\mathrm{PD}$ are conditions characterized by the disregulation of the host's inflammatory response, leading to damage or even loss of hard and soft support tissue. AS was correlated with other inflammatory diseases like Crohn's disease (CD), which there are certain characteristics linking AS and spondylitisassociated CD together based on sharing some of the genetic, clinical, immunological, and microbial features ${ }^{(6)}$. but its relation to PD is only beginning to be studied. Multiple studies support the role of PD in maintaining a biological inflammatory syndrome within a variety of chronic diseases, including AS, in which the inflammatory process is essential. It is believed that patients with AS are more likely to have PD compared to the healthy population. Epidemiological data provided by the literature on PD and AS indicate a similarity in the profiles of the two groups of patients ${ }^{(7,8)}$.

While the association between rheumatoid arthritis (RA) and periodontitis is well known, certain similarities between rheumatoid arthritis (RA) and AS are among the main reasons to hypothesis a link between periodontitis and AS may also exist ${ }^{(9,10)}$.

It has been suggested that rheumatic diseases may have additional underlying factors in common with chronic periodontitis. However, few studies have addressed the possible link between AS and chronic periodontitis.

In epidemiological research there are mainly three outcome criteria used for the clinical diagnosis of periodontitis: clinical attachment loss (CAL), Plaque index (PI) and pocket probing depth (PPD). Periodontitis is more common in male and persons of African-American race, is associated with specific gene polymorphisms as well as enviromemtal factors such as smoking and stress ${ }^{(1)}$.

\section{PATIENTS AND METHODS}

\section{Patient sample:}

The case-control study included 90 individuals, 45 documented patients with AS and another 45 clinically healthy individuals with PD as a control group. Among studied individuals, 65 were males and 25 were female.Individuals with systemic disease, had fixed or removal orthodontic appliance and less than 20 years old age were excluded from the study.

\section{1-AS patients}

Patients with AS had been diagnosed by rheumatologists in the specialized center of 
rheumatic disease and medical rehabilitation and referred to the department of periodontics, college of Dentistry, University of Duhok.

\section{2- Control patients}

Control patients included those individuals who visited periodontal department, college of Dentistry, University of Duhok without any systemic diseases except periodontal problems.A detailed periodontal examination was performed in all subjects, included probing pocket depth, epithelial insertion level (clinical attachment loss) and plaque index ${ }^{(7,12)}$. A probe was inserted into the area between the tooth and the periodontal tissue and lowered down to where the connective tissue attaches to the tooth ${ }^{(7)}$. The study was approved by an Ethical committee at the College of Medical, University of Duhok and a form of questionnaires was filled from the patients included gender, age, duration of AS disease, medication, risk factors of PD like smoking and level of education.

\section{Statistical analysis}

Data were analyzed by SPSS 24. Categoral data were described using frequency percentage tables. Numerical data were described by the mean, standard deviation and range. Association between categoral variables were tested by Chi square test, and when this was inappropriate, by Fisher's exact test. Differences between groups of numerical variables were tested by the unpaired t-test, and in case of more than two groups by one-way analysis of variance (with Sidak post-hoc test when significant). A $p$-value $\leq 0.05$ was considered significant.

\section{RESULTS}

The sociodemographic and clinical characteristics of the two study patients were described as shown in table 1. No significant differences were found in two studied groups based on age groups, level of education, smoking, duration of disease and the type of used drugs, but a significant difference was found between two groups based on gender in which AS was more common among males than females.

The means of three periodontal indices namely PI, PPD and CAL were compared between AS patients and control patients as shown in table 2 .

The mean of plaque index in control group was higher than the AS group. Similarly, control group had higher mean of CAL as compare to AS group, while AS group had higher mean of PPD as compare to control group. No significant differences were found in the mean of PI, PPD and CAL between AS and control groups.

The measurements of three studied periodontal indices were shown in table 3 . No significant differences were found in the measurements of three indices between AS and PD groups.

The mean of PI in AS patients according to the age groups, gender, level of education, smoking, duration of disease and type of received drugs as shown in table 4 . The high mean of PI was found in age group (50-60), males, illiterate, smokers, duration of disease (less than 5) and in patients receiving remicade.

The mean of PPD in AS patients according to the age groups, gender, level of education, smoking, duration of disease and type of received drugsas shown in table 5. The high mean of PPD was found in age group (50-60), males, primary, smokers, duration of disease (15-35) and in patients receiving remicade.

The mean of CAL in AS patients according to the age groups, gender, level of education, smoking, duration of disease and type of received drugsas shown in table 6 . The high mean of CAL was found in age group (50-60), males, illiterate, smokers, duration of disease (less than 5) and in patients receiving remicade. 
TABLE (1) Sociodemographic and clinical characteristics of the two study samples.

\begin{tabular}{|c|c|c|c|c|c|c|}
\hline \multirow[t]{2}{*}{ Characteristic } & & \multicolumn{2}{|c|}{ AS } & \multicolumn{2}{|c|}{ Controls } & \multirow[b]{2}{*}{$P$-value* } \\
\hline & & No. & $\%$ & No. & $\%$ & \\
\hline \multirow{5}{*}{$\begin{array}{l}\text { Age groups } \\
\text { (years) }\end{array}$} & $20-29$ & 8 & 17.8 & 18 & 40.0 & \multirow{4}{*}{0.021} \\
\hline & $30-39$ & 21 & 46.7 & 17 & 37.8 & \\
\hline & $40-49$ & 11 & 24.4 & 10 & 22.2 & \\
\hline & $50-59$ & 5 & 11.1 & 0 & & \\
\hline & Mean $\pm \mathrm{SD}$; range & \multicolumn{2}{|c|}{$37.7 \pm 8.5 ; 23.0-57.0$} & \multicolumn{2}{|c|}{$32.4 \pm 7.6 ; 21.0-47.0$} & \\
\hline \multirow[t]{2}{*}{ Gender } & Male & 40 & 88.9 & 25 & 55.6 & \multirow{2}{*}{0.001} \\
\hline & Female & 5 & 11.1 & 20 & 44.4 & \\
\hline \multirow[t]{4}{*}{ Level of education } & Illiterate & 20 & 44.4 & 15 & 33.3 & \multirow{4}{*}{0.632} \\
\hline & Primary & 9 & 20.0 & 8 & 17.8 & \\
\hline & Secondary & 8 & 17.8 & 11 & 24.4 & \\
\hline & High school & 8 & 17.8 & 11 & 24.4 & \\
\hline \multirow[t]{2}{*}{ Smoking } & Smoker & 22 & 50.0 & 14 & 31.1 & \multirow{2}{*}{0.110} \\
\hline & Not smoker & 22 & 50.0 & 31 & 68.9 & \\
\hline \multirow{5}{*}{$\begin{array}{c}\text { Duration of } \\
\text { disease } \\
\text { (years) }\end{array}$} & $<5$ & 10 & 22.2 & & & \\
\hline & $5-9.9$ & 14 & 31.1 & & & \\
\hline & $10-14.9$ & 15 & 33.3 & & & \\
\hline & $15-35$ & 6 & 13.3 & & & \\
\hline & Mean \pm SD; range & \multicolumn{2}{|c|}{$9.44 \pm 7.10 ; 0.25-35.0$} & & & \\
\hline \multirow[t]{3}{*}{ Type of drug } & Enbrel & 31 & 68.9 & & & \\
\hline & Remicade & 10 & 22.2 & & & \\
\hline & Humira & 4 & 8.9 & & & \\
\hline \multicolumn{2}{|c|}{ Total } & 45 & 100.0 & 45 & 100.0 & \\
\hline
\end{tabular}

* Based on Chi square or Fisher's exact test.

SD, standard deviation.

Table (2) The two study samples using the mean of three periodontal indices

\begin{tabular}{|c|c|c|c|c|c|c|c|}
\hline & \multicolumn{3}{|c|}{$\mathrm{AS}(\mathrm{n}=45)$} & \multicolumn{3}{|c|}{ Controls $(n=45)$} & \multirow[b]{2}{*}{$P$-value* } \\
\hline & Mean & SD & Range & Mean & $\mathrm{SD}$ & Range & \\
\hline PI & 1.61 & 1.29 & $0.40-8.80$ & 1.67 & 0.74 & $0.60-3.10$ & 0.774 \\
\hline $\mathrm{PPD}(\mathrm{mm})$ & 2.19 & 1.70 & $0.0-5.70$ & 1.97 & 1.21 & $0.12-4.10$ & 0.485 \\
\hline $\mathrm{CAL}(\mathrm{mm})$ & 1.81 & 1.39 & $0.0-6.40$ & 2.35 & 1.16 & $0.40-4.80$ & 0.048 \\
\hline
\end{tabular}


TABLE (3) Periodontal indices measurements in patients with AS and control group

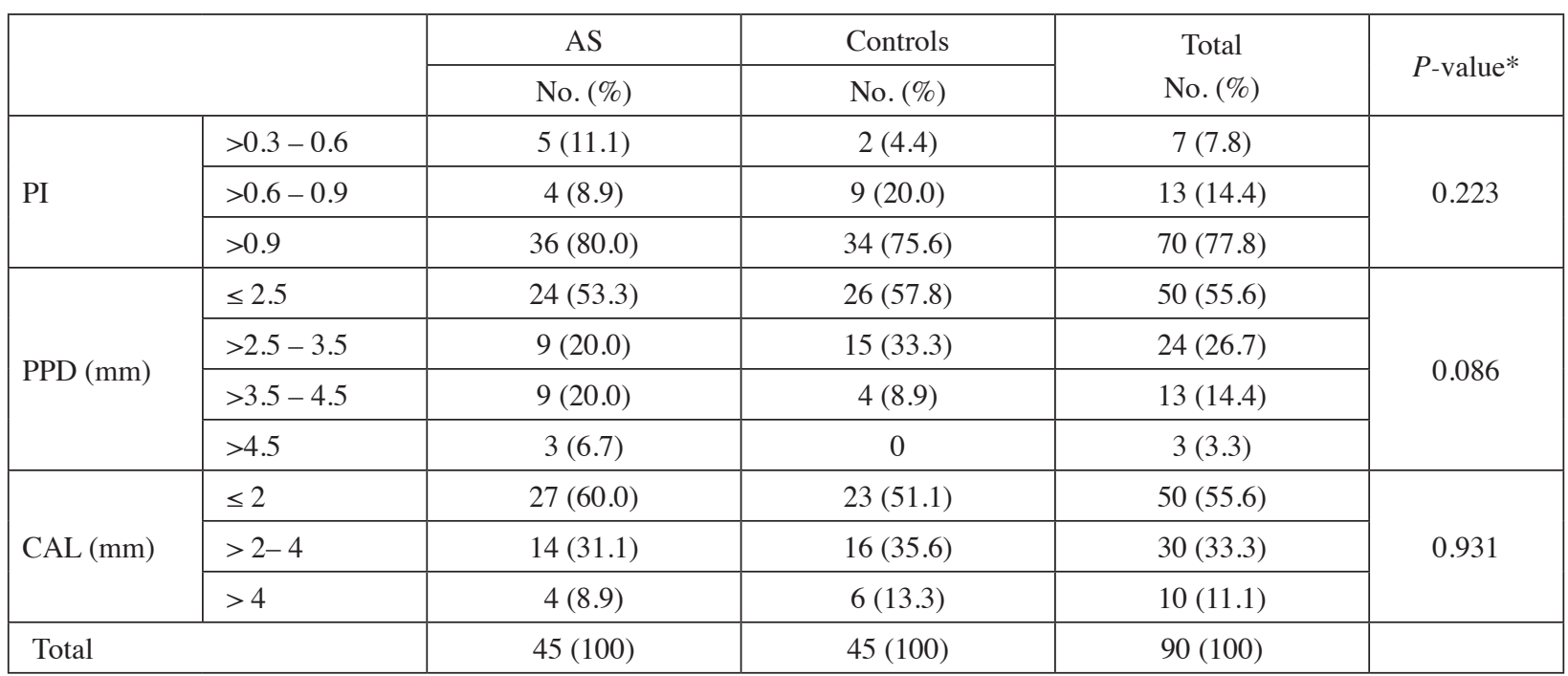

* Based on Chi square or Fisher's exacttest.

TABLE (4) Plaque index (PI) of patients with AS $(n=45)$, by their sociodemographic and clinical characteristics

\begin{tabular}{|c|c|c|c|c|c|}
\hline Characteristic & & Mean & SD & Range & $P$-value* \\
\hline \multirow[t]{4}{*}{ Age (years) } & $20-29$ & 1.40 & 0.71 & $0.40-2.80$ & \multirow{4}{*}{0.890} \\
\hline & $30-39$ & 1.72 & 1.75 & $0.60-8.80$ & \\
\hline & $40-49$ & 1.46 & 0.71 & $0.50-2.50$ & \\
\hline & $50-59$ & 1.83 & 0.69 & $0.90-2.80$ & \\
\hline \multirow[t]{2}{*}{ Gender } & Male & 1.64 & 1.36 & $0.40-8.80$ & \multirow{2}{*}{0.619} \\
\hline & Female & 1.34 & 0.34 & $1.08-1.90$ & \\
\hline \multirow[t]{4}{*}{ Level of education } & Illiterate & 1.90 & 1.72 & $0.50-8.80$ & \multirow{4}{*}{0.585} \\
\hline & Primary & 1.33 & 0.73 & $0.60-2.80$ & \\
\hline & Secondary & 1.29 & 0.55 & $0.40-2.20$ & \\
\hline & High school & 1.52 & 0.97 & $0.55-3.60$ & \\
\hline \multirow[t]{2}{*}{ Smoking } & Smoker & 1.70 & 1.68 & $0.60-8.80$ & \multirow{2}{*}{0.644} \\
\hline & Not smoker & 1.52 & 0.76 & $0.40-3.60$ & \\
\hline \multirow{4}{*}{$\begin{array}{l}\text { Duration of disease } \\
\text { (years) }\end{array}$} & $<5$ & 2.17 & 2.40 & $0.55-8.80$ & \multirow{4}{*}{0.424} \\
\hline & $5-9.9$ & 1.57 & 0.85 & $0.40-3.60$ & \\
\hline & $10-14.9$ & 1.29 & 0.51 & $0.60-2.20$ & \\
\hline & $\geq 15$ & 1.57 & 0.76 & $0.50-2.80$ & \\
\hline \multirow[t]{3}{*}{ Type of drug } & Enbrel & 1.45 & 0.76 & $0.40-3.60$ & \multirow{3}{*}{0.324} \\
\hline & Remicade & 2.15 & 2.38 & $0.50-8.80$ & \\
\hline & Humira & 1.47 & 0.51 & $0.90-2.10$ & \\
\hline Total & & 1.61 & 1.29 & $0.40-8.80$ & \\
\hline
\end{tabular}

* Based on one-way analysis of variance or unpaired t-test. $\quad S D$, standard deviation. 
TABLE (5) Probing pocket depth(PPD) of patients with AS $(n=45)$, by their sociodemographic and clinical characteristics

\begin{tabular}{|c|c|c|c|c|c|}
\hline Characteristic & & Mean & $\mathrm{SD}$ & Range & $P$-value* \\
\hline \multirow[t]{4}{*}{ Age (years) } & $20-29$ & 1.23 & 1.59 & $0.0-4.00$ & \multirow{4}{*}{0.063} \\
\hline & $30-39$ & 1.91 & 1.62 & $0.0-4.40$ & \\
\hline & $40-49$ & 2.99 & 1.83 & $0.0-5.70$ & \\
\hline & $50-59$ & 3.14 & 0.90 & $2.50-4.70$ & \\
\hline \multirow[t]{2}{*}{ Gender } & Male & 2.26 & 1.73 & $0.0-5.70$ & \multirow{2}{*}{0.435} \\
\hline & Female & 1.62 & 1.50 & $0.0-3.00$ & \\
\hline \multirow[t]{4}{*}{ Level of education } & Illiterate & 2.27 & 1.81 & $0.0-5.00$ & \multirow{4}{*}{0.916} \\
\hline & Primary & 2.38 & 1.37 & $0.0-4.10$ & \\
\hline & Secondary & 2.16 & 1.50 & $0.0-4.20$ & \\
\hline & High school & 1.81 & 2.18 & $0.0-5.70$ & \\
\hline \multirow[t]{2}{*}{ Smoking } & Smoker & 2.30 & 1.92 & $0.0-5.70$ & \multirow{2}{*}{0.687} \\
\hline & Not smoker & 2.09 & 1.51 & $0.0-4.20$ & \\
\hline Duration of disease & $<5$ & 1.76 & 1.88 & $0.0-4.10$ & \multirow{4}{*}{0.827} \\
\hline \multirow[t]{3}{*}{ (years) } & $5-9.9$ & 2.35 & 1.97 & 0.05 .70 & \\
\hline & $10-14.9$ & 2.21 & 1.56 & $0.0-4.40$ & \\
\hline & $15-35$ & 2.48 & 1.35 & $0.50-4.70$ & \\
\hline \multirow[t]{3}{*}{ Type of drug } & Enbrel & 2.12 & 1.72 & $0.0-5.70$ & \multirow{3}{*}{0.865} \\
\hline & Remicade & 2.45 & 1.80 & $0.0-5.00$ & \\
\hline & Humira & 2.08 & 1.76 & $0.0-3.90$ & \\
\hline Total & & 2.19 & 1.70 & $0.0-5.70$ & \\
\hline
\end{tabular}

* Based on one-way analysis of variance or unpaired t-test.

SD, standard deviation.

TABLE (6) Clinical attachment loss $(\mathrm{CAL})$ of patients with AS $(n=45)$, by their sociodemographic and clinical characteristics

\begin{tabular}{|c|c|c|c|c|c|}
\hline \multicolumn{2}{|l|}{ Characteristic } & Mean & SD & Range & $P$-value* \\
\hline \multirow[t]{4}{*}{ Age (years) } & $20-29$ & 0.99 & 0.95 & $0.0-2.60$ & \multirow{4}{*}{$<0.001 * *$} \\
\hline & $30-39$ & 1.44 & 1.06 & $0.0-3.10$ & \\
\hline & $40-49$ & 2.35 & 1.63 & $0.90-6.40$ & \\
\hline & $50-59$ & 3.54 & 0.82 & $2.30-4.30$ & \\
\hline \multirow{2}{*}{ Gender } & Male & 1.78 & 1.46 & $0.0-6.40$ & \multirow[b]{2}{*}{0.271} \\
\hline & Female & 2.10 & 0.37 & $1.70-2.50$ & \\
\hline \multirow[t]{4}{*}{ Level of education } & Illiterate & 2.08 & 1.25 & $0.0-4.40$ & \multirow{4}{*}{0.584} \\
\hline & Primary & 1.45 & 1.23 & $0.21-4.20$ & \\
\hline & Secondary & 1.44 & 1.06 & $0.0-3.10$ & \\
\hline & High school & 1.95 & 2.11 & $0.0-6.40$ & \\
\hline \multirow[t]{2}{*}{ Smoking } & Smoker & 1.86 & 1.71 & $0.0-6.40$ & \multirow[b]{2}{*}{0.818} \\
\hline & Not smoker & 1.77 & 1.03 & $0.0-4.20$ & \\
\hline \multirow[t]{4}{*}{ Duration of disease } & $<5$ & 1.42 & 0.89 & $0.0-2.70$ & \multirow{4}{*}{0.524} \\
\hline & $5-9.9$ & 1.75 & 1.96 & $0.0-6.40$ & \\
\hline & $10-14.9$ & 1.86 & 1.04 & $0.21-3.70$ & \\
\hline & $15-35$ & 2.50 & 1.26 & $0.80-4.20$ & \\
\hline \multirow[t]{3}{*}{ Type of drug } & Enbrel & 1.81 & 1.38 & $0.0-6.40$ & \multirow{3}{*}{0.339} \\
\hline & Remicade & 2.17 & 1.55 & $0.0-4.40$ & \\
\hline & Humira & 0.95 & 0.71 & $0.0-1.50$ & \\
\hline \multicolumn{2}{|l|}{ Total } & 1.81 & 1.39 & $0.0-6.40$ & \\
\hline
\end{tabular}

* Based on one-way analysis of variance or unpaired t-test.

** The older group is significantly different from the two young age groups but not from the 40-49 group.

$S D$, standard deviation. 


\section{DISCUSSION}

AS and PD are two conditions characterized by an altered inflammatory response of the patient, resulting in the destruction of the hard and soft connective tissue. Currently there are only three studies aiming to investigate the association between the two conditions, of which two have shown a higher prevalence of PD in patients diagnosed with AS, and periodontal disease more severe in patients with AS.

It is interesting to note that treatment for chronic periodontitis did not greatly affect the association between the two conditions. We believe that this result suggests that the mechanism underlying the association detected in this study is not one that can be simply explained through the inflammatory contribution of chronic periodontitis, but is instead an underlying alteration of immune function, as previous research has suggested ${ }^{(7,10,13)}$. However, while there is growing evidence suggesting that rheumatic diseases in general may share pathogenic factors in common with chronic periodontitis, including the abovementioned dysfunction of fundamental inflammatory mechanisms and an imbalance of proinflammatory and antiinflammatory cytokines ${ }^{(10-20)}$, only 2 prior studies to date have been conducted investigating the association between AS and chronic periodontitis specifically ${ }^{(7,14)}$.

The first study suggesting an association was performed on 77 patients representing a range of rheumatic diseases and 77 age- and sex-matched controls. The investigators found that all the rheumatic disease patients included in their study had various alterations in salivary flow and composition, as well as in oral health, and were more likely than controls to have a severe periodontal condition (58\% versus $\left.26 \% ; P \_0.0001\right)^{(10)}$. The second investigation performed regarding this association was a cross-sectional study conducted on a total of 48 patients with AS and 48 matched controls. While the investigators entered AS, age, sex, education, smoking, alcohol consumption, and body mass index into their logistic regression model, they only found age and education to be significant predictors for chronic periodontitis. Therefore, after adjusting for age and education, they found patients with AS to have a6.81-fold (95\% CI 1.96-23.67) increased odds of chronic periodontitis compared to controls (7).

In fact, our analysis suggests that poor oral hygiene (table 3 ), as determined by higher PI, 5 individuals with $(>0.3-0.6), 4$ individuals with $(>0.6$ $0.9)$ and 36 individuals with $(>0.6)$ attenuates the association between AS and periodontal attachment loss to some extent. The analysis includes 27 individuals with $\leq 2,14$ individuals with $>2-4$ and 4 individuals with $>4$. However, the results also indicate that high plaque accumulation may only partially account for this association and that other parameters may be like the mediators responsible for the increased prevalence of PD in individuals with AS.

The sample size of our study was relatively small, which may limit the precision of the risk estimates.

While the measure of association we detected in this study was substantially lower than that detected previously, we believe that our estimate is likely to more accurately reflect the true nature of the association based on several factors. First, limited number of AS cases in Duhok, and thus was unable to attain the statistical power provided by large number of patients in other studies. Second, all the patients in the study were recruited from the Specialized center of rheumatic disease and medical rehabilitation of Duhok health director of a single center, which may have introduced a selection bias. Third, Due to the small number of patients, the majority of whom were males, there was a significant difference in gender. Fourth, the mismatch in the age groups between the two groups is due to the small number of AS patients. 
Fifth, There was no significant difference between the two groups when comparing the results of (PI,PPD and CAL) because the control patients had periodontal problems because they were reviewing the periodontal disease department in the college of dentistry to treat them and we took these patients for our study randomly while most of the studies that were done previously the control group did not have periodontal problems. Our results differ from previous studies on the association between AS and chronic periodontitis.

Several other aspects that may have an influence on the possible link between the two diseases are still not clarified. For instance, both Keller et al. ${ }^{(8)}$ and Sezer et al. ${ }^{(12)}$ came to the conclusion that the explanation for the underlying mechanism of the association must be attributed in great part to a factor other than an inflammatory contribution. Furthermore, Sezer et al. ${ }^{(12)}$ found that the periodontal status of AS patients might be affected by IL-6levels and Keller et al. ${ }^{(8,12)}$ reported that the association between periodontitis and AS was reduced by having had a gingivectomy or periodontal flap surgery.

These results suggest that an association may exist between AS and periodontal disease. Such an association would be important since knowledge of an effect of periodontal treatment on AS disease activity or vice versa would lead to the need for close collaboration between rheumatologists and dentists when treating these diseases. Moreover, since studies have shown that both periodontal disease and AS decrease quality of life, an essential factor to consider would be how strongly a patient'squality of life is influenced by suffering from both periodontal disease and AS. However, given the small number of studies with important methodological weaknesses, there is a need for a study with sufficient statistical power to detect the desired effect size, taking into account potential confounding factors and using validated measures of AS and periodontitis. Such study would involve collaboration between rheumatologists, dentists and epidemiologists.

\section{Recommendation}

We recommend conducting research in larger numbers and comparing them with healthy people and the community directly.

\section{REFERENCES}

1. Alexandru G.Croitorul,Dan Piperea-Sianul, Carina Mihail, Alice Piperea-Sianu, Adela Maria Ceaul, Daniela Badita, Victoria Arama, Stefan SorinArama. pathophysiological correlations between ankylosing spondylitis and periodontal disease. The impact of ankylosing spondylitis therapy on periodontal tissue. Romanian Journal of Rheumatology 2015; vol:24,No.1,22.

2. Eke P, Barker L. Prevalence of Periodontal Disease in the United States: NHANES 1999-2004. IADR, 2007.

3. Tiara Ratz, Linda Dean, Fabiola Atzeni, Chris Reeks, Tatiana Macfarlane .Periodontal disease and ankylosing spondylitis: a Systematic review. Prospero NHS 2013;CRD 420130062209

4. Firesteain G., Budd R., Gabriel S. et al. Kelley's Textbook of Rheumatology, Elsevier, 2013, ISBN:9781437717389

5. Sengupta R, Stone M..The assessment of ankylosing spondylitis in clinical practice. Nat Clin Pract Rheumatol 2007; 3:496-503.

6. A. Ebringer, T. Rashid, H. Tiwana, and C. Wilson, "A possible link between Crohn's disease and ankylosing spondylitis via Klebsiella infections," Clinical Rheumatology, vol. 26, no. 3, pp. 289-297, 2007.

7. Pischon N., Pischon T., Gülmez E et al. Periodontal disease in patients with ankylosing spondylitis, Annals of the rheumatic diseases, 2010; 69:34-38

8. Keller J.J., Kang J.H., Lin H.C. Association between ankylosing spondylitis and chronic periodontitis: a population-based study, Arthritis and rheumatism, 2013; 65:167-173

9. Pischon N, Pischon T, Kroger J. Association Among Rheumatoid Arthritis, Oral Hygiene and periodontitis. J Periodontol 2008.79;979-86.

10. Bartold PM, Marshall RI, Haynes DR. Periodontitis and Rheumatoid Arthritis: A review.JPeriodontol 2005. 76; 2066-74. 
11. Chang SH, Lee JT, Choi BY et al. 2013 Periodontal disease is not associated with ankylosing spondylitis and TNFalpha blockers usage in Korea [abstract]. Arthritis Rheum; 65(Suppl 10):2476.

12. Sezer U, Erciyas K, Üstün K et al.2012. Serum cytokine levelsand periodontal parameters in ankylosing spondylitis.J Periodont Res;47:396-401.

13. Preshaw PM, Taylor JJ. How has research into cytokine interactions and their role in driving immune responses impacted our understanding of periodontitis? J Clin Periodontol 2011; 38 Suppl 11:60-84.

14. Helenius LM, Meurman JH, Helenius I, Kari K, Hietanen $\mathrm{J}$, Suuronen R, et al. Oral and salivary parameters in patients withrheumatic diseases. Acta Odontol Scand 2005; 63:284-93.

15. Loos BG. Systemic markers of inflammation in periodontitis. J Periodontol 2005;76:2106-15.

16. Schett G. Review: immune cells and mediators of inflammatory arthritis. Autoimmunity 2008;41:224-9.
17. Pischon N, Pischon T, Kroger J, Gulmez E, Kleber BM, Bernimoulin JP, et al. Association among rheumatoid arthritis, oralhygiene, and periodontitis. J Periodontol 2008; 79:979-86.

18. de Pablo P, Dietrich T, McAlindon T. Association of periodontal disease and tooth loss with rheumatoid arthritis in the US population. J Rheumatol 2007;35:70-6.

19. Mercado FB, Marshall RI, Klestov AC, Bartold PM. 2001. Relationship between rheumatoid arthritis and periodontitis. J Periodontol; 72:779-87.

20. Al-Katma MK, Bissada NF, Bordeaux JM, Sue J, Askari AD. 2007. Control of periodontal infection reduces the severity of active rheumatoid arthritis. J Clin Rheumatol; 13:134-7.

21. Suppiah P,Cullinan M, Nolan A, Thompson WM, Stebbings $\mathrm{S}$. An association between periodontal disease, oral health related quality of life and disease activity in patients with ankylosing spondylitis [abstract] Rheumatology 2013;52:166-7. 